\title{
Hospital symbolic boundaries during the COVID-19 pandemic
}

\author{
Las fronteras simbólicas del hospital durante la pandemia de COVID-19
}

Liz Hamui-Sutton*

Division of Postgraduate Education, Faculty of Medicine, Universidad Nacional Autónoma de México, Mexico City, Mexico

The basic definition of "hospital" refers to the physical place or establishment destined to the diagnosis and treatment of sick people, where research and teaching are often practiced. The World Health Organization defines it as an "integral part of a social and medical organization, the function of which is to provide for the population complete health care, both curative and preventive, and whose out-patient services reach out to the family in its home environment". Its main function is to provide medical care, as well as to foster promotion, prevention, recovery and rehabilitation through emergency, outpatient and hospitalization services, among others.

Beyond its facilities, the hospital can be understood as a social space where interactions occur between agents that, on one hand, coordinate with each other in processes intended to provide care in case of illness (health team) and, on the other, subjects who need help and care to alleviate their ailments (patients and their families). In this sense, the hospital, as Castoriadis refers, ${ }^{2}$ is understood as an instituted and, at the same time, instituting dynamic organization, where acting forces exist that, based on certain regulations, carry out articulated and iterative tasks, but also improvisations, depending on the situation, to respond to the various interests that are at stake in the processes of care.

The hospital has been studied from the perspective of social sciences by authors such as Goffman, ${ }^{3}$ who describes hospitals as "total institutions", with more or less porous boundaries that delimit the inside from the outside, and where there is a formal administration that addresses the needs of those who dwell in the establishment. When being admitted, the sick person becomes a patient and has to abide by all hospital rules and regulations, becomes an object of medical scrutiny that from scientific and clinical rationality tries to find a solution to his/her health problems. By considering medical care to be preponderant, other aspects of patient identity and daily life are minimized; his/her world of life, beliefs, values and preferences become secondary, as well as his/her emotions and affective bonds, which are dosed or suppressed. For example, although the patient might feel shame when coexisting with other unknown patients, he/she is placed in collective wards to be monitored by a health team that he/she also does not know; his/her body is exposed and he/she is kept away from his/her surroundings, although, actually, given the fear of their illness, many patients feel safer in the hospital despite the restrictions.

Time and space are perceived differently within the hospital. When the symbolic border from the outside to the inside is crossed, patient biographical and social time is put on hold, to remain immersed in hospital time, in medical practices and at the mercy of the other agents involved in the care and administrative rituals of the hospital. Social interactions within the
Gac Med Mex. 2021:157:217-219

Contents available at PubMed

www.gacetamedicademexico.com license (http://creativecommons.org/licenses/by-nc-nd/4.0/). 
clinical space are traversed by the articulations and tensions of the activities of those who participate in the process of care. It is a network organization that brings on interdependence, which can be more or less free-flowing in a single area or in the coordination of departments.

Healthcare tasks are regulated by hierarchies that imply chains of command and collaborative work, for example, of staff doctors, nurses, residents, interns, undergraduate students, auxiliary personnel in the areas of laboratory, nutrition, physiotherapy, palliative care, social work, pharmacy, administration, housekeeping, etc. Clinical weaves are constructed on activity strips and are documented in medical records and clinical notes, in such a way that a record remains on the performance of each individual who intervenes. This has implications not only in terms of efficiency for restoring patient health, but also in legal issues associated with successful or failed performance. Interactions take regulations into account in order to adhere to them, but also to calculate deviances in the resolution of concrete situations. This way, medical care results in a constant negotiation between what is possible and what is necessary, which gives rise to improvisation.

With the emergence of the COVID-19 pandemic, numerous secondary and tertiary care hospitals have found themselves in the imminent need to transform usual hospital order to deal with the care of SARSCoV-2-affected patients. Uncertainty in the presence of an unprecedented disease and the risk of contagion within the hospital bring about radical changes in its symbolic boundaries. Access to people unconnected to the hospital is radically restricted; COVID-19 patients are received outside the hospital where their condition is evaluated and the disease is confirmed by PCR testing. This is the last moment the family has contact with the patient, and sometimes farewells are rather dramatic due to the possibility of not seeing each other again. Fear of death as a primary existential emotion emerges over and over again at hospital space threshold.

The transition from the outside to the inside in fact means a rupture of the social and affective bond, the passage to a place where the patient's body becomes a clinical object. Inside, biomedical logic prevails and sociocultural and emotional dimensions become invisible given the seriousness of the possible outcome of the case. When conscious, dispossessed of his/her social relationships, the patient experiences a sort of loneliness while waiting, adapting to hospital times and spaces, to healthcare schedules, to the rhythms and guidelines of clinical interactions.

From the perspective of the healthcare team, hospital facilities reconversion and new logistics for the care of patients with COVID-19 also represent a big challenge. Hospital work becomes threatening, both for healthy healthcare personnel and for those who have risk factors or comorbidities. Workers have to deal with new clinical practice manuals and guidelines for updating themselves on the procedures and algorithms to be followed. Healthcare groups are created with at least one intensivist for cases of intubation, different specialists for hospitalized patients who require oxygen and other types of care, at least one person in the laboratory, nurses in the intensive care unit and hospitalization areas, orderlies and cleaning staff. All of them with protective equipment and extreme security protocols to prevent the risk of contagion. Space and time at hospitals are transformed in terms of rhythms and routines, which generates conflicts in the coordination for patient isolation. Tension increases, since participants become jointly responsible for avoiding security breaches that might result in infection transmission and the possibility of death.

Efficiency in the process of COVID-19 patients care, as well as in the handling of dead bodies, becomes essential. However, treatment success is relative: out of every 10 intubated patients, seven die in isolation conditions, without seeing their loved ones again. The scenes of family members collecting the corpse of their relative are recurrent, with a great burden of suffering, sadness, anguish and depression. This radical separation and compliance with the exacerbated rules and regulations of clinical environment, as well as hospital overcrowding, drives many people to choose not to attend the hospital and try to alleviate the symptoms of the COVID-19 patient at home, even if they know that he/she is not going to live.

In social imaginary, the hospital represents a place to die, a space of uprooting, an ascetic liminal place between life and death, away from everyday life and significant beings. The person, turned into a biological body is dispossessed of his/her identity, his/her biography, his/her social relationships and his/her culture. The notion of the hospital as an unwanted place is also reinforced by images in the media, by the epidemiological narrative of federal, state and local authorities. Nobody wants to be just another number in daily statistics of the sick and dead from COVID-19. 
In the desperation of not knowing what to do, family members try to avoid following the itinerary of going from one hospital to another and the patient being rejected due to lack of space. Social time of those outside and clinical time of those inside the hospital is stressed and experiences a major break that causes social suffering. The question that arises then is: in view of the uncertainty of the situations caused by COVID-19, is it possible for an alternative social order to be established in the hospital that considers emotional and sociocultural aspects of patients?

\section{References}

1. World Health Organization [Internet]. Switzerland: Hospitals; 2021.

2. Castoriadis C. La institución imaginaria de la sociedad. Mexico: Fábula Tusquets Editores; 2013

3. Goffman E. Internados: ensayos sobre la situación social de los enfermos mentales. Buenos Aires: Amorrortu Editores; 1972. 